Goldschmidt 2021 Abstract

https://doi.org/10.7185/gold2021.5773

\section{Mobility of selected Less Studied Technology Critical Elements (Ge, Te, TI) in soils affected by the storage, processing and recovery of e-waste}

\author{
MAGDALENA ANNA JABLOŃSKA-CZAPLA ${ }^{1}$, \\ MARZENA RACHWAL ${ }^{1}$, KATARZYNA GRYGOYĆ $^{1}$, \\ AGNIESZKA FORNALCZYK ${ }^{2}$, JOANNA WILLNER ${ }^{2}$ AND \\ PIOTR ZERZUCHA ${ }^{3}$
}

${ }^{1}$ Polish Academy of Sciences

${ }^{2}$ Silesian University of Technology

${ }^{3}$ The Pontifical University of John Paul II

Presenting Author: magdalena.czapla@ipispan.edu.pl

The development of electrical and electronic industry, rapid consumption and "ageing" of the equipment entail the necessity of regular replacement, which increases the amount of electrical and electronic waste (called just e-waste or WEEE). E-waste is a specific type of waste, that is a source of potentially toxic elements (Potentially Toxic Elements - PTE), including TCE (Technology Critical Elements). Worn e-waste after getting into the environment become a potential source of TCE. Therefore, the European Union (European COST Action TD1407: Network on Technology-Critical Elements) draw the attention of the scientific community to investigate the content of these elements in various elements of the environment and the impact of environmental processes on the forms of their occurrence, as well as threats to human health caused by them. For example, germanium in the human body accumulates in organs and can cause inflammation and cancer. Thallium toxicity is high and depends on its form. Due to the easy assimilation of tellurium by living organisms, local contamination of the environment with this element can be an environmental threat.

The research concerned the influence of the WEEE processing plant on the content and mobility of selected critical elements in soils in the surrounding areas. In the work, sequential chemical extraction was used to determine the mobility of $\mathrm{Te}, \mathrm{Tl}$ and $\mathrm{Ge}$ in the areas under pressure of the WEEE processing plant.

The concentration of TCE was the highest in the topsoil and was decreasing in the soil profile. Our research results have evidenced an increase of the germanium and tellurium content in soils in the close vicinity of the WEEE processing plant, significantly exceeding the geochemical background content (Figure 1). Tellurium was bound mainly with sulphides, organic matter and silicates. Germanium and thallium in the studied soils were strongly demobilized in the residual fraction (Figure 2).

The work is the result of an ongoing project entitled „Research on the mobility of selected critical elements (TCE - Technology Critical Elements) and their species in soils in areas related to the storage and processing of electrowaste" funding from the National Science Centre of Poland UMO-2018/ 29/B/ST10/01522.

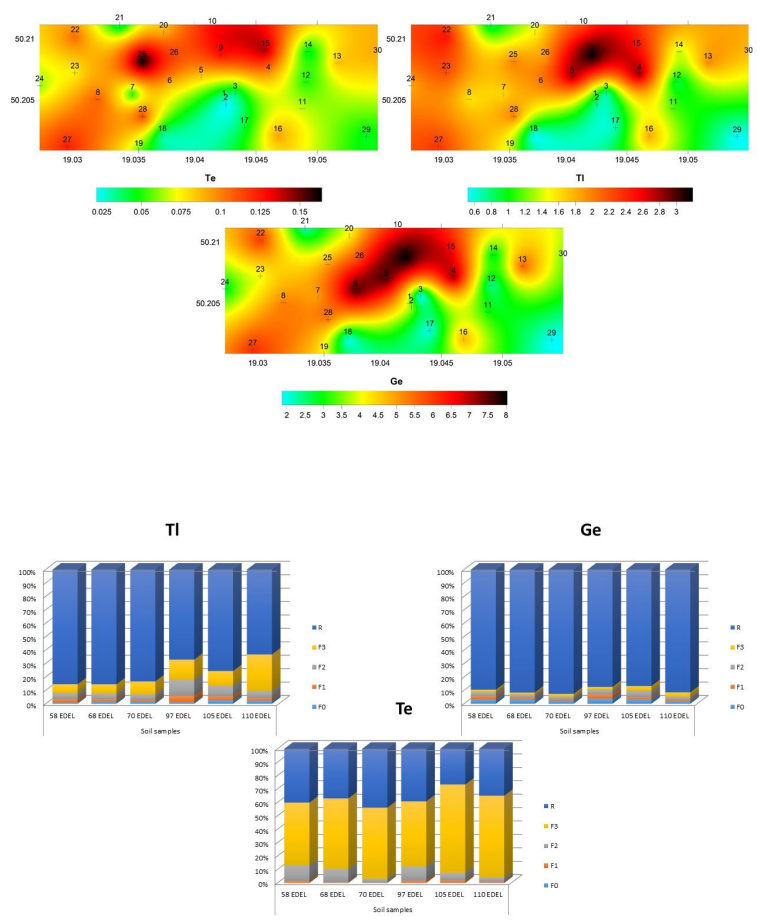

